\title{
The different character of the recent eruptions of Galápagos shield volcanoes (Ecuador): La Cumbre vs. Sierra Negra
}

\author{
By Francisco Vasconez ${ }^{1}$, Patricio Ramón ${ }^{1}$, Stephen Hernandez ${ }^{1}$, Silvana Hidalgoㄹ, Benjamin Bernard1, Mario \\ Ruiz $^{1}$, Alexandra Alvarado1, Peter La Femina², Gorki Ruiz ${ }^{2,3}$ \\ 1Instituto Geofísico de la Escuela Politécnica Nacional, Ladrón de Guevara E11-253, Quito, Ecuador. \\ 2The Pennsylvania State University, University Park, Pennsylvania 16802, Pennsylvania, USA. \\ ${ }^{3}$ Universidad Central del Ecuador, Jerónimo Leyton \& Avenue La Gasca, Quito, Ecuador.
}

\begin{abstract}
In the last year, two Galápagos volcanoes had shown eruptive activity. The three observed eruptions produced multiple lava flows along eruptive fissures and vents covering several square kilometers. After eight years of quiescence, La Cumbre volcano, Fernandina Island experienced two short-lived eruptions, on 4 September 2017 and 16 June 2018. The eruptions were characterized by very short periods of unrest that started a few hours before the initiation of the eruptive activity. On the other hand, Sierra Negra volcano, Isabela Island, began a new eruptive period on 26 June, after almost one year of persistent unrest characterized by an increase in the magnitude and number of seismic events and more than 5 meters of uplift since its last eruption in 2005. The Sierra Negra and La Cumbre eruptions were located in remote zones where access is extremely complex. Thus, satellite images allowed us to: 1) complement the continuous monitoring data of the Instituto Geofísico (IG-EPN) with remote observations such as the appearance and distribution of the eruptive plumes and the evolution of the thermal anomalies along the ongoing eruptions; and 2) do a rapid response mapping in order to identify the areas affected by the lava flows, which threaten the native flora and fauna of the islands.

\section{SUMMARY OF THE ERUPTIONS}

La Cumbre (Fernandina Island):

After 8 years of quiescence, La Cumbre $\left(0.37^{\circ} \mathrm{S}, 91.55^{\circ} \mathrm{W}, 1476 \mathrm{~m}\right.$ a.s.l.), the westernmost volcano of the Galápagos Archipelago began a new eruptive phase on 4 September 2017. At 11h34 UTC the IG-EPN monitoring network detected an increase in hybrid seismic events related either to fracturing and/or fluid or path effects, which presented an energy peak at 16h20 UTC. Seismic signals changed at 17h25 UTC from hybrid to Low Frequency events (LF) related to fluid motion (gas and/or magma) and finally at 18h25 UTC volcanic tremor was recorded. This tremor was associated with the beginning of the eruption and extrusion of lava flows (Figure 1a).
\end{abstract}



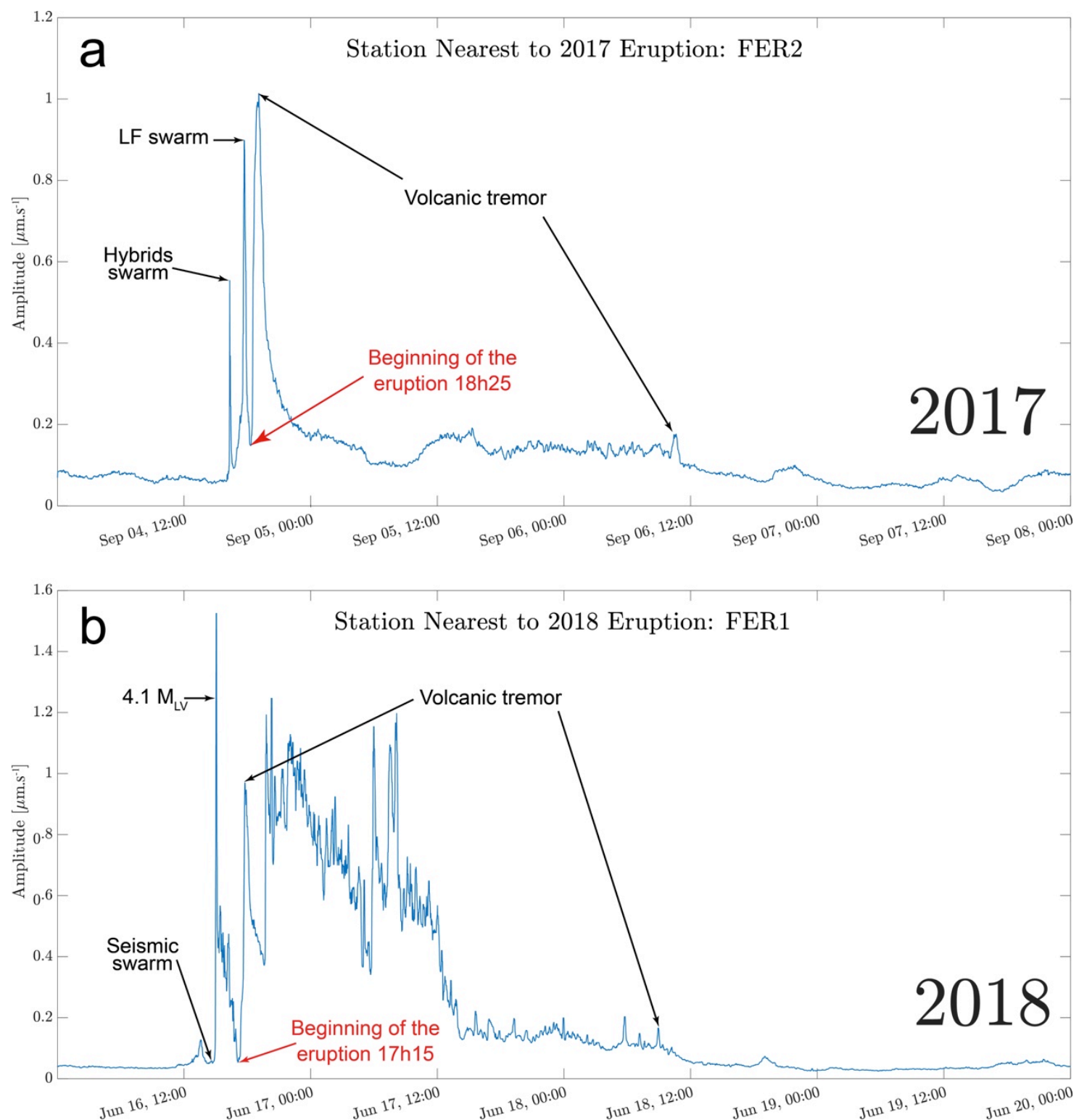

Figure 1. RSAM data in 10-minute windows during two La Cumbre volcano eruptions. Traces are corrected for instrument response and filtered between 1 - 8 Hz.: a) 2017, seismic station FER2 and b) 2018, seismic station FER1.

Additionally, Interferometric Synthetic Aperture Radar (InSAR) detected an uplift of 17 centimeters from March 2015 to September 2017 (Figure 2) on the floor of the caldera $\left(31 \mathrm{~km}^{2}\right)$, the final five centimeters of which occurred in the last two months before the eruption. 


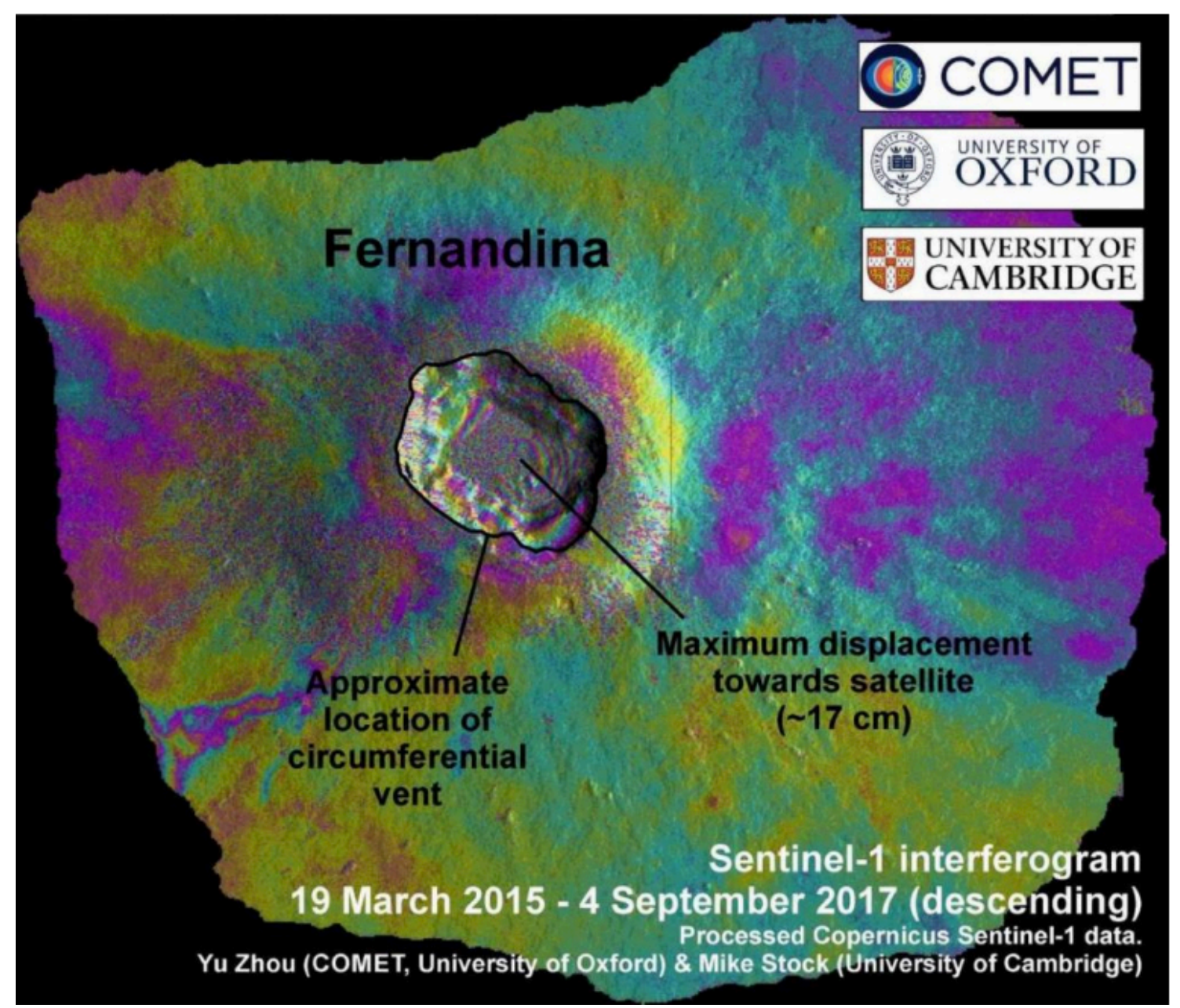

Figure 2. Interferogram between 19 March 2015 and 4 September 2017. The caldera floor shows an uplift of $17 \mathrm{~cm}$ (Source: Yu Zhou y Mike Stock in IGEPN 2017).

The first thermal anomaly detected by GOES-16 satellite close to the caldera rim was at $18 \mathrm{~h} 30 \mathrm{UTC}$, five minutes after the onset of the eruption based on volcanic tremor (Figure 1a). The eruption generated a column that reached $4000 \mathrm{~m}$ a.s.l., composed mainly of volcanic gases with low ash content drifting to the west. The eruption originated from a three kilometer long arcuate fissure located on the southwestern upper-flank of the volcano, at the same location as the 2005 (Chadwick et al. 2011; Bagnardi, Amelung, and Poland 2013). The fissure emitted several lava flows that covered an area of $6.5 \mathrm{~km}^{2}$ (Figure 3). The maximum runout of the flows was four kilometers downslope. These lava flows did not reach the ocean. After two and a half days, a decrease in the seismic energy back to background levels indicated that the eruption concluded (Figure 1a).

$\mathrm{SO}_{2}$ degassing was clearly seen by OMI and OMPS satellite instruments. The higher $\mathrm{SO}_{2}$ mass observed by OMPS was on September 5 reaching $8.2 \mathrm{kt}$.

The most dangerous hazard associated with this eruption was the series of wildfires triggered by the high temperatures of the lava flows and the prevailing surface wind direction. The fires burned an area of $16 \mathrm{~km}^{2}$ on the western flank where endemic fauna and flora were present (Figure 3). The MIROVA and FIRMS satellite systems augmented the IG-EPN monitoring efforts during this period and 
allowed us to monitor the wildfires, which ended one month after the eruption concluded.

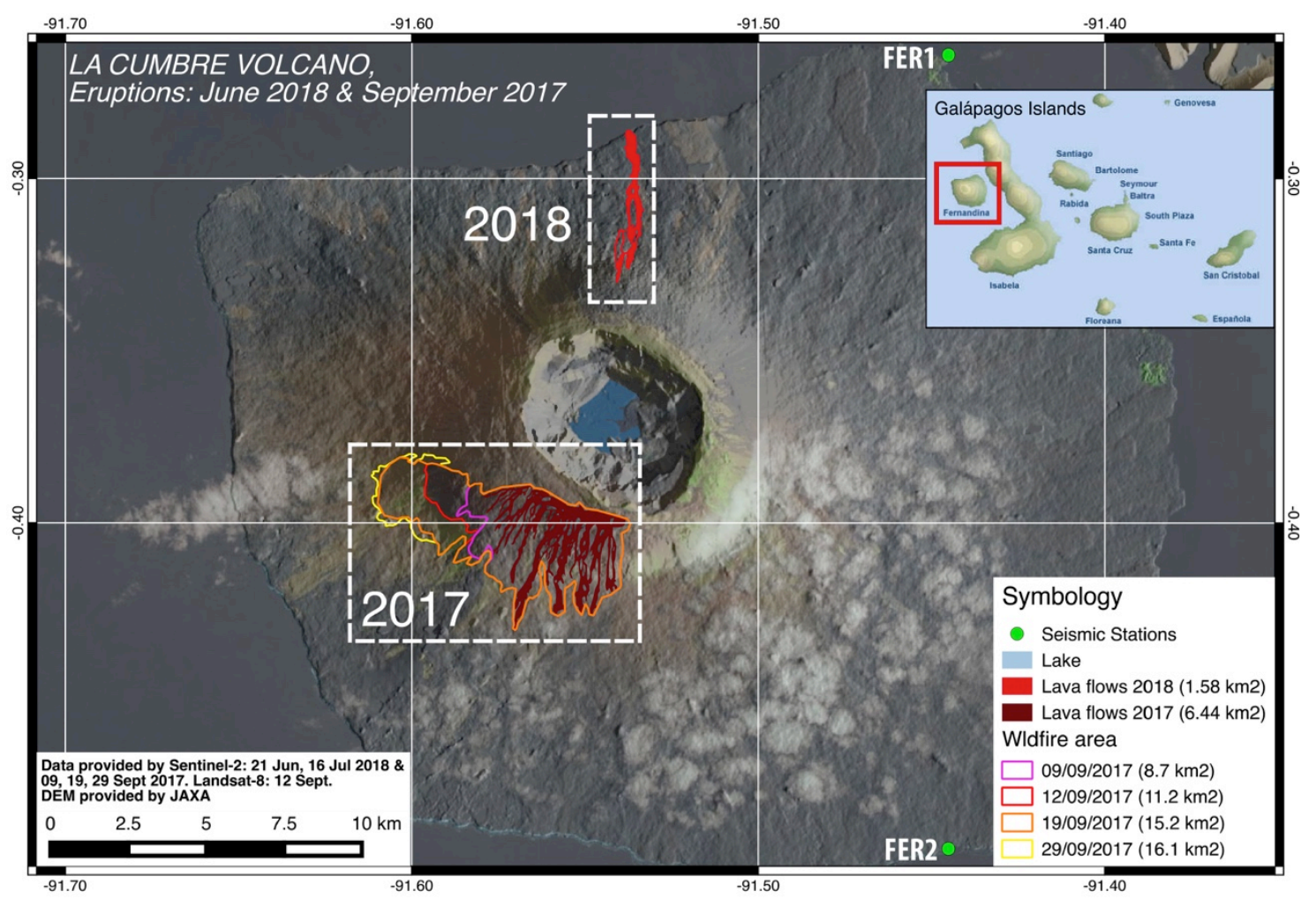

Figure 3. Map of the eruptions of "La Cumbre" volcano in September 2017 and June 2018. Note color lines showing the area burnt by wildfires triggered by the lava flows and the prevailing wind during the 2017 eruption. Green dots are the location of the seismic stations FER1 \& FER2.

On 16 June 2018, nine months after the last eruption, a new period of unrest began. The seismic monitoring network of the IG-EPN detected nine earthquakes larger than $2.5 \mathrm{M}_{\mathrm{LV}}$, starting at $14 \mathrm{~h} 37 \mathrm{UTC}$, with the largest event of $4.1 \mathrm{M}_{\mathrm{LV}}$ occurring at 15h22 UTC. At 17h15 UTC volcanic tremor was observed indicating the beginning of the eruption and lava emission (Figure $1 \mathrm{~b}$ ). The eruption occurred on the northern flank of the volcano $1.5-2 \mathrm{~km}$ downslope of the caldera rim (Figure $3)$. It produced an eruptive column of volcanic gases and low ash content drifting to the southwest. The radial fissures were 100-200 meters long and extruded lava flows that reached the ocean ( $4 \mathrm{~km}$ run-out) and covered $1.58 \mathrm{~km}^{2}$ (Figure 3). Similar to the previous eruption, this ended two days after of the seismic activity began (Figure $1 \mathrm{~b}$ ). $\mathrm{SO}_{2}$ degassing reached a minimum of $32 \mathrm{kt}$ according to the OMPS image of July 17.

\section{Sierra Negra:}

Sierra Negra volcano $\left(0.81^{\circ} \mathrm{S}, 91.13^{\circ} \mathrm{W}, 1124 \mathrm{~m}\right.$ a.s.l. $)$ is located at the southern end Isabela Island. Its last eruption, in 2005, was characterized by the extrusion of 150 million cubic meters $\left(150 \mathrm{Mm}^{3}\right)$ of lava flows that covered a large part of the caldera floor and a smaller area to the north of the caldera (Geist et al. 2008). According to Global Volcanism Program (2013), Sierra Negra averages one eruptive period every 11-12 years with most of the recent activity located on the northern flank and inside its vast caldera $\left(82 \mathrm{~km}^{2}\right)$. 
Since July 2017, persistent signals of unrest were detected by the IG-EPN. Thousands of earthquakes $(>15,000)$ located inside and at the rim of the caldera were recorded at shallow depths (1-15 km). Many of them were larger than $3 \mathrm{M}_{\mathrm{LV}}$ and some even larger than $4 \mathrm{M}_{\mathrm{LV}}$ (11 seismic events). Galápagos National Park rangers housed at the touristic rim entrance, called "El Cura", regularly felt the largest earthquakes. These events also produced small rockfalls at the walls of the caldera. Most of these seismic events were volcano-tectonic (VT) events related to rock fracturing, but Low-Frequency (LF), Very Low-Frequency (VLF) and hybrid events probably caused by the motion of rising magma and gases were also recorded. The number and magnitude of the seismic events increased significantly until the beginning of the eruption in June 2018.

A high-precision GPS (cGPS) network installed by UNAVCO, University of Idaho, and Oregon State University, and now maintained by Penn State University and UNAVCO, detected more than 4.5 meters of vertical uplift since 2006 (Figure 4). This ground deformation constitutes the most dramatic uplift recorded in any volcanic area in the world. InSAR images processed at the Rosenstiel School of Marine and Atmospheric Science (RSMAS, https://insarmaps.miami.edu/) confirm this result and detected a cumulative uplift of 2.46 meters on the caldera floor since December 2014 (Figure 4). According to the cGPS network, since January 2018 the uplift rate accelerated and was close to 11 centimeters per month. No obvious changes in the deformation rate were observed before the eruption began. 

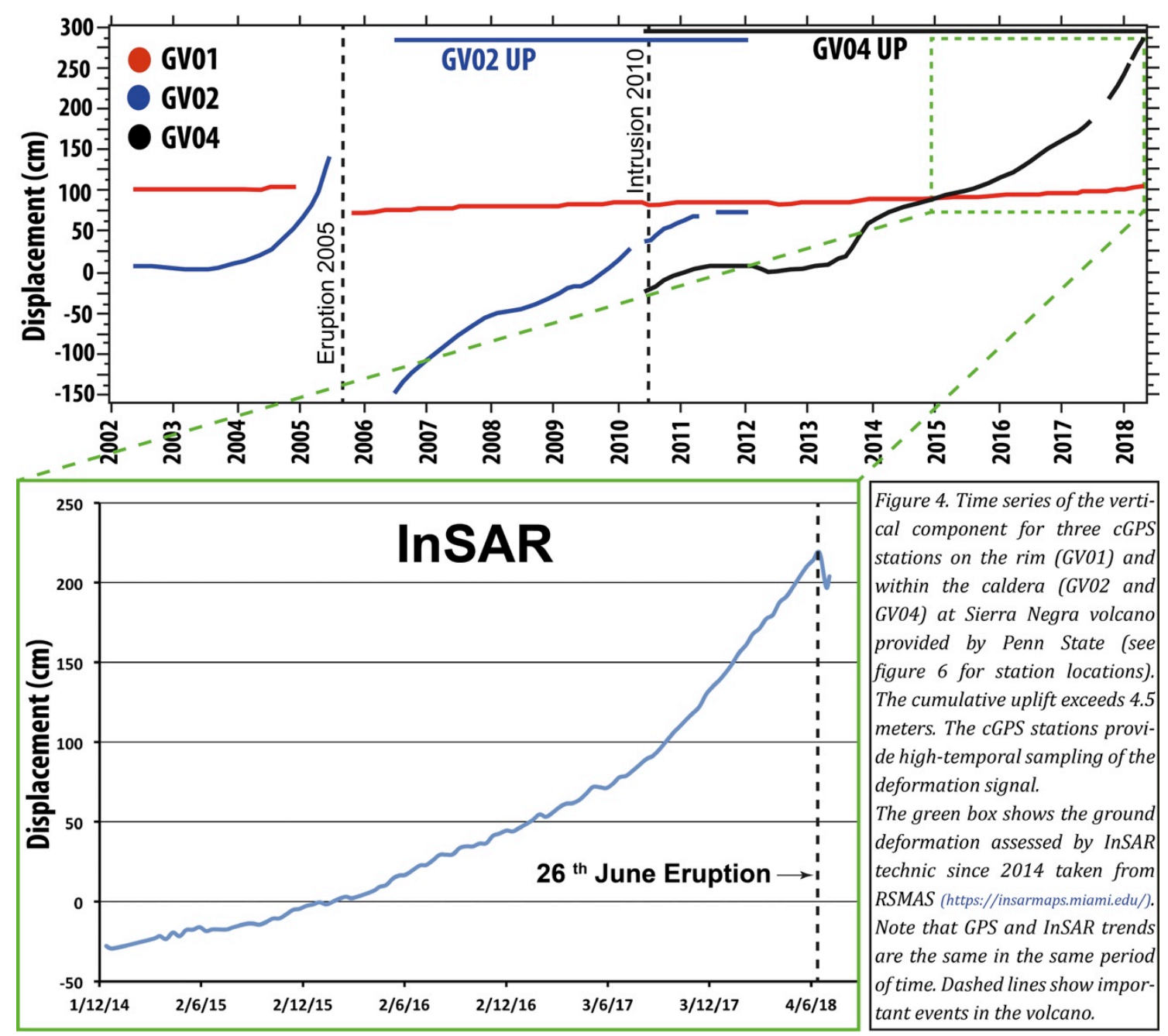

On Tuesday, June $26^{\text {th }} 2018$ at $9 \mathrm{~h} 15$ UTC, a $5.3 \mathrm{M}_{\mathrm{Lv}}$ earthquake with a focal mechanism indicating reverse slip occurred near the southwestern caldera rim at $5.3 \mathrm{~km}$ depth (Figure 5a, 6). This earthquake was large enough to be felt and reported by residents in nearby Puerto Villamil, which is the main urban zone located $19 \mathrm{~km}$ southeast of the epicenter. After a few hours of relative seismic quiescence, at 17h17 UTC, an intense seismic swarm commenced and included a 4.6 $\mathrm{M}_{\mathrm{LV}}$ earthquake and several VLF, VT and LF events embedded in the sequence. Finally, at $19 \mathrm{~h} 40$ UTC volcanic tremor began to dominate the seismic record indicating the beginning of the eruption (Figure 5a). 

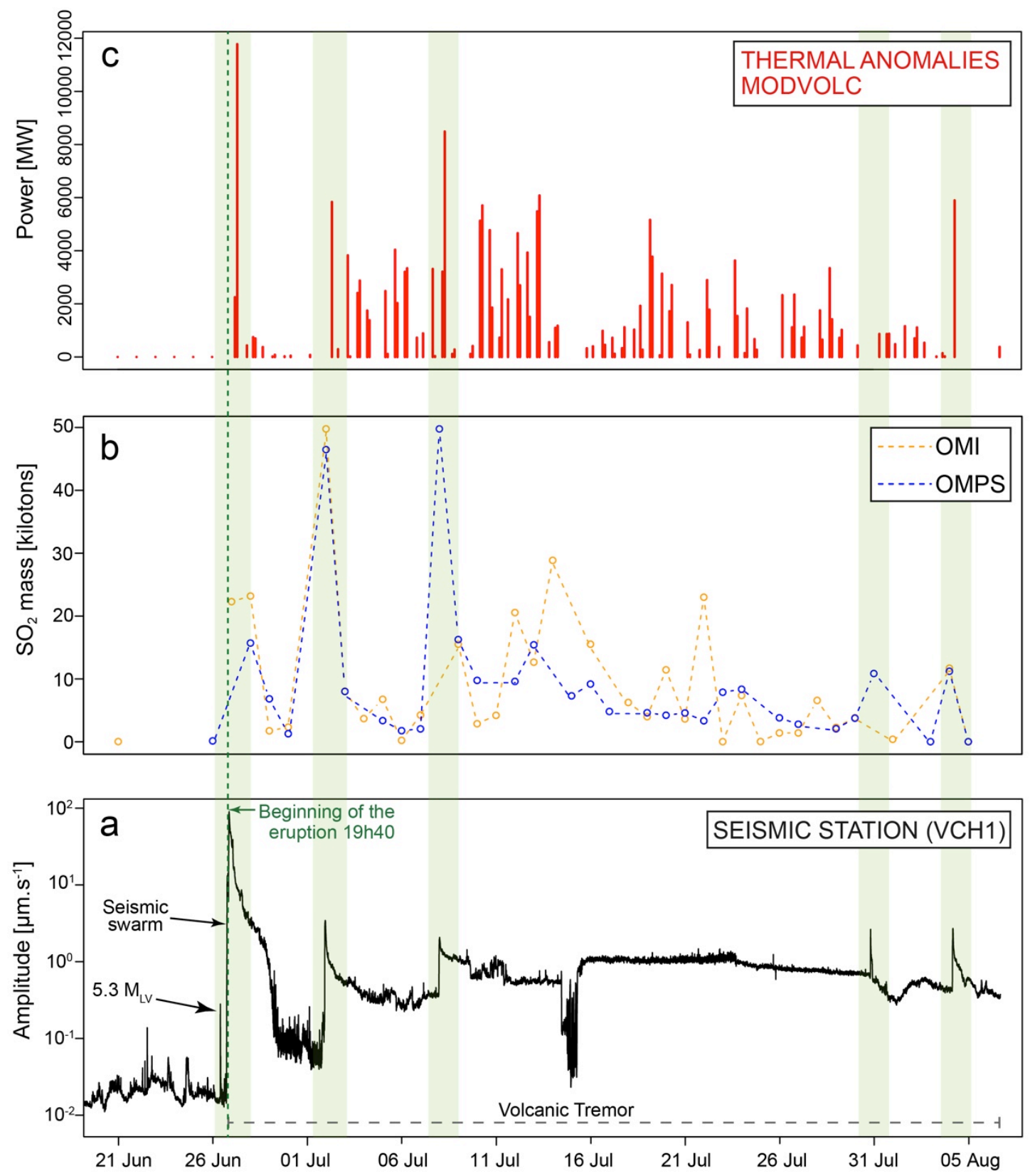

Figure 5. Composite image of the monitoring parameters at Sierra Negra volcano, from 21 June to 26 July 2018. Green dashed-line marks the beginning of the eruption and green bars show the main eruptive pulse. a) RSAM data (station VCH1) in 10-minute windows are corrected for instrument response and filtered between $1-8 \mathrm{~Hz}$. b) Time series of $\mathrm{SO}_{2}$ mass recorded by OMI and OMPS satellite instruments. Data downloaded from https://so2.gsfc.nasa.gov/pix/daily/0718. c) Thermal anomalies recorded by MODVOLC. Data downloaded from http://modis.higp.hawaii.edu/.

GOES-16 satellite images identified an eruptive column of volcanic gases at 10.5 $\mathrm{km}$ a.s.l. drifting to the northwest. Thermal anomalies at the northern flank of the caldera were also identified. The eruption occurred along four fissures (Figure 6). 


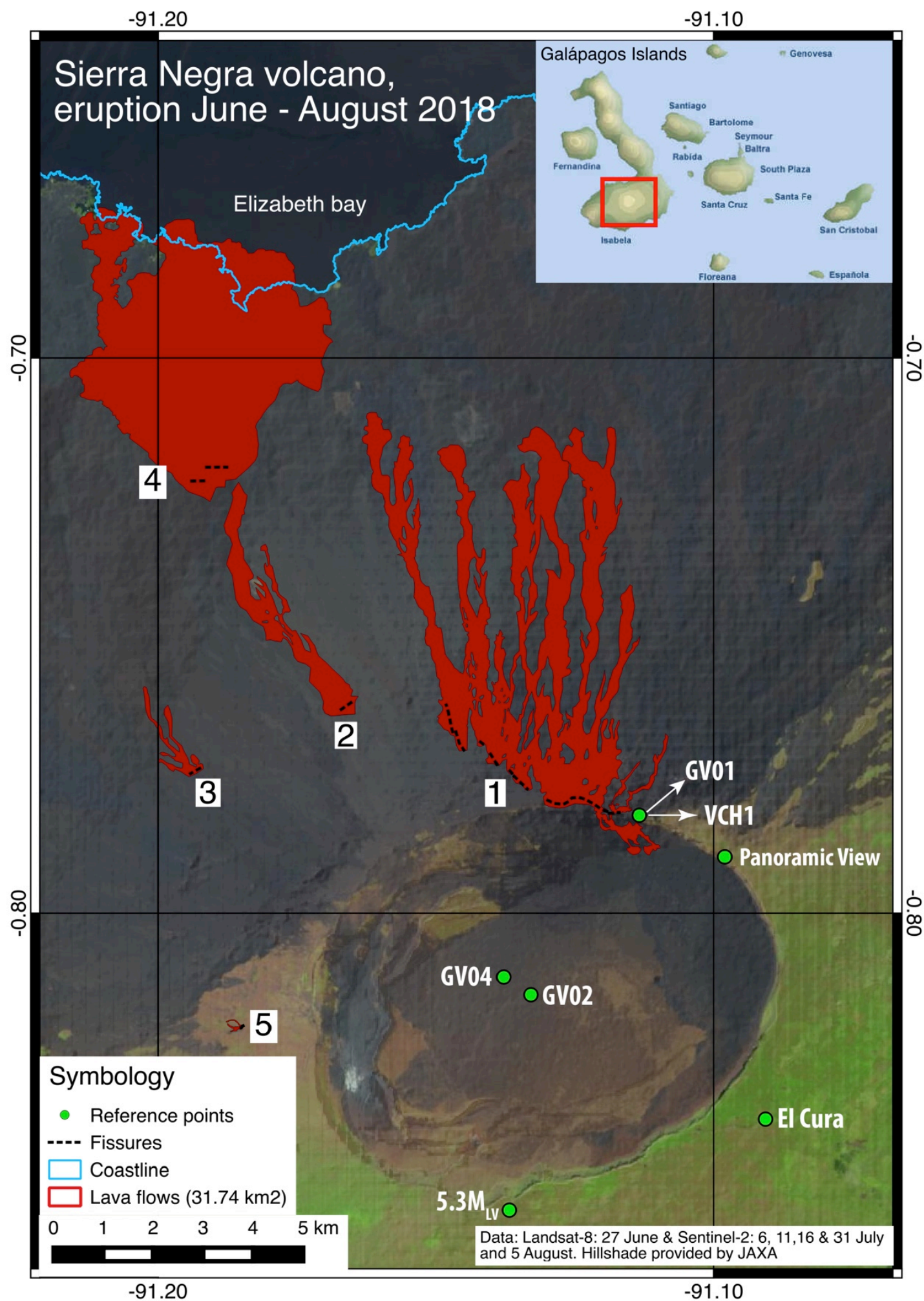

Figure 6. Map of 2018 Sierra Negra eruptive fissure and lava flows. The map is for the time period from 26 June to 5 August. Green dots are the main reference locations, which include cGPS and seismic permanent stations, epicenter of the earthquake $\mathrm{M}_{\mathrm{LV}} 5.3$ and the panoramic view visited by tourist.

- Fissure one (1070 m a.s.l.) is a tangential fissure of four kilometers in length and aligned WNW to the caldera rim located in the "Volcán Chico" sector. This 
fissure produced a lava fountain that extruded several lava flows covering 14.7 $\mathrm{km}^{2}$ in one day of activity. The maximum run-out of these flows was seven kilometers downslope.

- Fissures two (700 $\mathrm{m}$ a.s.l.) and three (550 $\mathrm{m}$ a.s.l.) are located to the northwest and west of the caldera, three and four kilometers downslope of the rim, respectively. These fissures were approximately 250 meters long and produced lava flows that covered $2.3 \mathrm{~km}^{2}$ and $0.4 \mathrm{~km}^{2}$, respectively in a single day of eruptive activity.

- Fissure four (100 m a.s.l.), is located on the northwestern flank at $8 \mathrm{~km}$ north of the caldera rim, and is the most active and currently the only vent with ongoing activity. The most recent data indicates that flows covered an area of $14.4 \mathrm{~km}^{2}$; however, at the time of writing the area is still growing. Therefore most of the volume of the eruption is concentrated in this flat area. According to Sentinal-1 data collected on 6 July, lava flows reached the ocean and began to change the Ecuadorian coastline. Up to 5 August, the Ecuadorian territory increased about $1.5 \mathrm{~km}^{2}$. Important hazards associated with this phenomenon are explosions due to rapid evaporation as the hot lavas enter the cold ocean.

- Finally, fissure five (840 m a.s.l.), is located on the west $1.5 \mathrm{~km}$ downslope of the caldera rim (Marco Bagnardi personal comm.). It is 170 meters long and produce $0.026 \mathrm{~km}^{2}$ of lava flows.

Until 05 August, we estimated that the lavas emitted by this eruption cover a total area of $31.74 \mathrm{~km}^{2}$, which is comparatively equivalent to the area occupied by Cuenca, the third largest city in Ecuador. Moreover, we estimate a bulk volume of 160-200 million $\mathrm{m}^{3}$, assuming $1 \& 3$ meters thickness on fissures $1,2,3 \& 5$, and 10 meters thickness on fissure 4. Finally, a magnitude of 4.6 and intensity of 8 was calculated for the eruption so far.

Finally, the seismic record showed four eruptive pulses on 1-2, 7-8, 31 July and 4 August (Figure 5a). OMI and OMPS satellite instruments show the complete evolution of $\mathrm{SO}_{2}$ degassing during this eruption. The peaks on $\mathrm{SO}_{2}$ emissions perfectly follow the pulses on seismic amplitude (Figure 5a), showing the higher values at the beginning of the eruption around $29 \mathrm{kt}$, and on July 2 and 8, with values of $46 \mathrm{kt}$ and $50 \mathrm{kt}$ respectively. Daily values are typically higher than $3 \mathrm{kt}$ (Figure 5b). These pulses were also recorded by MODVOLC system, which detected the evolution of thermal anomalies (Figure 5c). The pulses are related to an increase in the eruptive emission rate of lava flows at fissure four, which formed a scoria cone.

\section{Conclusions}

- La Cumbre and Sierra Negra are both shield volcanoes fed by magma from the same hot spot, which showed similar eruptive style. Nonetheless, their unrest periods reported here were quite different.

- It seems that Sierra Negra usually shows a clear and long-lasting unrest period characterized by an increase in the number and magnitude of volcanic earthquakes and is also accompanied by significant ground deformation of the caldera floor (i.e., 2005 \& 2018 eruptions). Moreover, the $\mathrm{M}_{\mathrm{LV}} 5.3$ earthquake was a clear precursor of the eruption, which was also the case in 2005 (Geist et al. 2008). On the other hand, La Cumbre 
volcano displayed short-lasting seismic unrest (few hours) and less impressive ground deformation in the last two eruptions (2017 \& 2018). Also, vents and fissures open up on different flanks of the volcano, which is more difficult to anticipate during the hazard assessment.

- These eruptions show that long-lasting unrest periods could be related with long-lasting eruptive periods, more than 40 days in the case of Sierra Negra volcano. On the other hand, short-lasting unrest in La Cumbre volcano produces a short eruptive periods (two days). This observation has a direct correlation with the volume of magma erupted, the intensity of the eruption and the risk assessment. Nonetheless, this observation has to be studied in depth because other volcanoes; for example, Wolf (Galápagos) showed short unrest period and long-lasting eruption (Bernard et al. 2015).

- Galápagos Archipelago is a fragile ecosystem with unique native flora and fauna. Both can be highly threatened by lava flows and wildfires as occurred during the La Cumbre eruption (Fernandina) in 2017.

- Satellite images provided critical information for hazard assessment and unrest and eruption monitoring in such remote areas. Freely available satellite data complement the monitoring network of the volcano observatory and help to improve the communication with the stakeholders.

\section{Acknowledgement}

The information presented in this short summary was provided by the special reports of the Instituto Geofísico de la Escuela Politécnica Nacional (IG-EPN, www.igepn.edu.ec). The authors thank all scientists who analyzed and interpreted the results presented in this article. Special acknowledgement to all the staff of IGEPN and to the international and national partners such as: InSAR data analysis provided by Rosenstiel School of Marine and Atmospheric Science (USA), and University of Oxford and Cambridge (UK), and cGPS analysis provided by The Pennsylvania State University (USA).

\section{References:}

Bagnardi, Marco, Falk Amelung, and Michael P. Poland. 2013. "A New Model for the Growth of Basaltic Shields Based on Deformation of Fernandina Volcano, Galápagos Islands." Earth and Planetary Science Letters 377-378 (September): 358-66. https://doi.org/10.1016/j.epsl.2013.07.016.

Bernard, B., P. Ramon, H. Wright, A. Guevara, S. Hidalgo, D. Pacheco, D. Narvaez, and F. Vasconez. 2015. "Preliminary Results on the 2015 Eruption of Wolf Volcano." In Isabela Island, Galápagos: Chronology, Dispersion of the Volcanic Products, and Insight into the Eruptive Dynamics, Abstract V31B-3022 Presented at 2015 Fall Meeting, AGU, San Francisco, Calif, 14-18.

Chadwick, William W., Sigurjon Jónsson, Dennis J. Geist, Michael Poland, Daniel J. Johnson, Spencer Batt, Karen S. Harpp, and Andres Ruiz. 2011. "The May 2005 Eruption of Fernandina Volcano, Galápagos: The First Circumferential Dike Intrusion Observed by GPS and InSAR." Bulletin of Volcanology 73 (6): 679-697. https://doi.org/https://doi.org/10.1007/s00445-010-0433-0.

Geist, Dennis J., Karen S. Harpp, Terry R. Naumann, Michael Poland, William W. Chadwick, Minard Hall, and Erika Rader. 2008. "The 2005 Eruption of Sierra Negra Volcano, Galápagos, Ecuador." Bulletin of Volcanology 70 (6): 655-73. https://doi.org/10.1007/s00445-007-0160-3. 
Global Volcanism Program, 2013. [Sierra Negra (353050)] in Volcanoes of the World, v. 4.7.1. Venzke, E (ed.). Smithsonian Institution. Downloaded 06 Aug $2018 \quad$ (https://volcano.si.edu/volcano.cfm?vn=353050). https://doi.org/10.5479/si.GVP.VOTW4-2013

IGEPN. 2017. "Special Report Fernandina N02." September 6, 2017. https://www.igepn.edu.ec/islas-galapagos-informes/gal-fernandina/gal-feespeciales/gal-fe-e-2017/18787-informe-especial-fernandina-n-02-2017. 